\title{
Local level of TGF- $\beta 1$ determines the effectiveness of dexamethasone through regulating the balance of Treg/Th17 cells in TNBS-induced mouse colitis
}

\author{
PENG YOU*, NING CHEN*, LIN SU*, TAO PENG, GUODONG CHEN and YULAN LIU \\ Department of Gastroenterology, Peking University People's Hospital, Beijing 100044, P.R. China
}

Received February 6, 2017; Accepted August 1, 2017

DOI: $10.3892 /$ etm.2018.5852

\begin{abstract}
Transforming growth factor $\beta 1$ (TGF- $\beta 1$ ) has a crucial role in regulating the balance of type 17 T-helper cells (Th17) and T regulatory cells (Tregs) that are involved in the pathogenesis of inflammatory bowel disease, while the function of local TGF- $\beta 1$ in this process has remained to be fully elucidated. The present study investigated the effects of different local TGF- $\beta 1$ levels on the Treg/Th17 balance and on the dexamethasone efficacy in mice with 2,4,6-trinitrobenzenesulfonic acid (TNBS)-induced colitis. Various TGF- $\beta 1$ levels in colon tissue were achieved by enema delivery of a high, medium or low amount of adenovirus expressing TGF- $\beta 1$ $\left(10^{7}, 10^{8}\right.$ or $10^{9} \mathrm{pfu}$, denoted as AdTGF-1, AdTGF-2 and AdTGF-3, respectively). Dexamethasone further decreased colon damage and myeloperoxidase activity in TNBS mice receiving AdTGF-1 and AdTGF-2. When AdTGF-1 was administered, dexamethasone enhanced its effect by reducing interferon (IFN) $-\gamma$ and increasing interleukin (IL)-10 production. In TNBS mice receiving AdTGF-2, the increase in IFN- $\gamma$, tumor necrosis factor- $\alpha$, IL-6, IL-17 and IL-23 was significantly prevented by dexamethasone treatment. In comparison with the lower doses, AdTGF-3 exerted the opposite effect on regulating the cytokine production in TNBS mice, which was not affected by dexamethasone treatment. In mesenteric lymph nodes, AdTGF-1 prevented the TNBS-induced reduction of Tregs and IL-10, and potentially increased the efficacy of dexamethasone. In addition, dexamethasone further decreased the levels of activated caspase 3 in TNBS mice receiving adenoviral TGF- $\beta 1$, particularly in the AdTGF-1 group. The activation of the p38 mitogen-activated protein kinase/c-Jun N-terminal kinase/c-Jun pathway was significantly inhibited
\end{abstract}

Correspondence to: Professor Yulan Liu, Department of Gastroenterology, Peking University People's Hospital, 11 Xizhimen South Street, Xicheng, Beijing 100044, P.R. China

E-mail: yopeng@163.com

*Contributed equally

Key words: 2,4,6-trinitrobenzenesulfonic acid, transforming growth factor- $\beta 1$, T regulatory cell, $T$ helper type 17 cell, dexamethasone by a low amount of TGF- $\beta 1$ administered to TNBS-treated mice, which was further decreased by dexamethasone. The present study provided evidence that the therapeutic effect of dexamethasone may depend on the local levels of TGF- $\beta 1$ in TNBS-induced colitis and may be mediated, at least partially, through promoting the differentiation of Tregs and thus altering the balance of pro- and anti-inflammatory cytokines.

\section{Introduction}

Inflammatory bowel disease (IBD) usually leads to severe diarrhea, pain, fatigue and weight loss, and sometimes causes life-threatening complications (1). The incidence of IBD is increasing each year, while the underlying molecular mechanisms remain to be fully elucidated. It is well known that IBD results from a defective mucosal immune response that ultimately promotes chronic inflammation of the entire or part of the digestive tract $(1,2)$. A crucial event in the development of IBD is that the high sensitivity to the bacterial microflora in the gastrointestinal tract induces severe autoimmunity enteritis, in which regulatory $\mathrm{T}$ (Treg) cells and the type 17 T-helper (Th17) cell subset are involved $(3,4)$. Treg cells, characteristically expressing the transcription factor Forkhead box p3 (Foxp3), are immunosuppressive and generally suppress or downregulate the induction and proliferation of effector T cells (4). In T cell-induced mouse colitis, colonic inflammation and damage are prevented by adoptive transfer of Treg cells (5). Furthermore, Treg cells regulate self-reactive lymphocytes via a variety of mechanisms, including secretion of inhibitory cytokines such as interleukin (IL)-10 and transforming growth factor- $\beta$ (TGF- $\beta$ ), granzyme-mediated cytolysis, cytotoxic T-lymphocyte-associated protein 4 induction, metabolic disruption and dendritic cell targeting (6). By inducing and/or maintaining Foxp3 expression, TGF- $\beta$ promotes the differentiation and maturation of Treg cells that inhibit the unwanted immune response and dampen inflammation after microbial infection (7). Mice deficient of IL-10 not only developed colitis, but also colon cancer at a high rate (8).

Of note, TGF- $\beta$ in conjunction with IL- 6 also leads to the production of Th17 cells, which predominantly produce IL-17, a potent pro-inflammatory cytokine (9). The inflamed gastrointestinal mucosa of patients with IBD exhibits an excessive infiltration of Th17 cells and Th17-associated cytokines, including IL-17, IL-6, IL-23 and interferon (IFN)- $\gamma$ in colon 
tissues (10). Hence, the dysregulation of cytokines driven by TGF- $\beta$ modulates intercellular communications, and thus has a crucial role in the pathogenesis of IBD. TGF- $\beta$, belonging to the TGF- $\beta$ superfamily, includes three major isoforms, TGF- $\beta 1$, -2 and 3 , secreted by a variety of cell types (11). Normally, a large amount of TGF- $\beta 1$ produced in the gastrointestinal tract is in its latent precursor form, requiring cleavage and dissociation for conversion to a mature bioactive dimer (12). Elevated expression of TGF- $\beta 1$ was detected in colon tissues from IBD patients (12). In mice, overexpression of consecutively activated TGF- $\beta 1$ by adenoviral delivery into the local colon tissue causes intestinal fibrosis (13), indicating a potential therapeutic target in the prevention of fibrosis in IBD. However, it has been demonstrated that overexpression of TGF- $\beta 1$ induces suppression of the Th1 cell response by upregulating IL-10 and downregulating IL-12 receptor $\beta 2$ chain (14), which has been proposed as a potential therapy for IBD.

The role of TGF- $\beta 1$ in inflamed colon disease is complex, as it is a multi-functional cytokine, which negatively as well as positively regulates the immune response. The present study provided evidence that the therapeutic effect of dexamethasone may depend on the local TGF- $\beta 1$ levels in 2,4,6-trinitrobenzenesulfonic acid (TNBS)-induced mouse colitis at least partially through promoting the differentiation of Treg cells and thus altering the balance of pro- and anti-inflammatory cytokines.

\section{Materials and methods}

TNBS-mediated induction and treatment of colitis in mice. A total of 92 male BALB/c mice (weight, 22.0-25.6 g; age, 8 weeks; Chinese Academy of Sciences, Beijing, China) were used in all experiments and were randomly divided into different groups of 4 animals each. All of the animal protocols were approved by the Experimental Animal Ethics Committee of Peking University People's Hospital (Beijing, China). All mice were given free to access to water and food, and housed in a pathogen-free animal facility maintained at $25^{\circ} \mathrm{C}$ with a relative humidity of $50 \pm 10 \%$, and illuminated by a 12-h light-dark cycle. For induction of colitis, mice were placed individually in an induction chamber and anaesthetised with 4\% enflurane (Isoflo; Esteve Farma, Lisboa, Portugal) in $100 \%$ oxygen at a delivery rate of $1.0 \mathrm{l} / \mathrm{min}$ until loss of movement. Following anaesthesia, $2.5 \mathrm{mg}$ TNBS (Sigma-Aldrich; Merck KGaA, Darmstadt, Germany) in $150 \mu 150 \%$ ethanol was administered through a $3.5 \mathrm{~F}$ catheter inserted $\sim 4 \mathrm{~cm}$ to the rectum. Control mice were treated with $150 \mu 150 \%$ ethanol. Mice were allowed to recover for $24 \mathrm{~h}$, and thereafter, the colitic mice were given a PBS enema containing $1 \times 10^{7}$, $1 \times 10^{8}$ or $1 \times 10^{9}$ pfu of adenovirus expressing full-length mouse TGF- $\beta 1$ (Vector Biolabs, Malvern, PA, USA). A proportion of the colitic mice receiving adenoviral TGF- $\beta 1$ were treated by oral gavage with $5 \mathrm{mg} / \mathrm{kg}$ body weight of dexamethasone (Sigma-Aldrich; Merck KGaA). All mice were sacrificed at the indicated time-points.

Macroscopical scoring. Tissue samples were excised and damage was evaluated by an investigator blinded to the grouping. As described previously (15), macroscopical damage was scored on a $0-10$ scale $(0$, normal; 1 , localized hyperemia, no ulcers; 2, ulceration without hyperemia or bowl wall thickening; 3, ulceration with inflammation at 1 site; 4, ulceration and inflammation at 2 or more sites; 5 , major sites of damage extended $>1 \mathrm{~cm}$ along length of colon; 6-10, when an area of damage extended $>2 \mathrm{~cm}$ along length of the colon, the score was increased by 1 for each additional $\mathrm{cm}$ of involvement).

Myeloperoxidase (MPO) and alkaline phosphatase (ALP) activity assay. Colon tissue (50 mg) was homogenized in 4 volumes of ice cold lysis buffer $(0.1 \%$ Nonidet $P(N P)-40 / P B S)$ using a Dounce homogenizer, and then centrifuged at $13,400 \mathrm{x} \mathrm{g}$ for $5 \mathrm{~min}$ at $4^{\circ} \mathrm{C}$. The supernatant was collected, the MPO activity was determined by using an MPO Activity detection kit (cat. no. ab111749; Abcam, Cambridge, MA, USA) and values were expressed as the unit per $g$ tissue. For evaluation of ALP activity, colon tissue protein was extracted with a lysis buffer composed of $20 \mathrm{mM}$ Tris- $\mathrm{HCl}$ (pH 7.5), $150 \mathrm{mM} \mathrm{NaCl}$ and $1 \%$ Triton X-100. The enzymatic activity of ALP was determined using a Diethanolamine assay (cat. no. AP0100; Sigma-Aldrich; Merck KGaA) and expressed as units per mg protein of tissue.

ELISA. The levels of TGF- $\beta 1$ (cat. no. ab119557), IL-17 (cat. no. ab100702), IL-23 (cat. no. cat. no. ab119545), IL-10 (cat. no. ab100697), IL-6 (cat. no. ab100712) and IFN- $\gamma$ (cat. no. ab100690; all Abcam) as well as tumour necrosis factor (TNF)- $\alpha$ (cat. no. 88-7324-22; Thermo Fisher Scientific, Inc., Waltham, MA, USA) were measured using ELISA according to the manufacturer's protocol.

Reverse-transcription quantitative polymerase chain reaction $(R T-q P C R)$. Total RNA was extracted from mesenteric lymph nodes with an RNeasy Mini kit (Qiagen, Hilden, Germany), and then reversely transcribed into complementary (c)DNA by using a cDNA Synthesis kit (Thermo Fisher Scientific, Inc.). The cDNA $(2 \mu 1)$ was used to perform quantitative PCR with 1X SYBR-Green Mix (Bio-Rad Laboratories, Inc., Hercules, CA, USA) and $250 \mathrm{nM}$ primers on a 7700 real-time PCR Detection System (Applied Biosystems; Thermo Fisher Scientific, Inc.) for detecting the expression of various genes with the following primers: RAR-related orphan receptor (ROR) $\gamma$ t forward, 5'-TTTTCCGAGGATGAGATTGC-3' and reverse, 5'-CTTTCCACATGCTGGCTACA-3'; Foxp3 forward, 5'-CAGCTCTGCTGGCGAAAGTG-3' and reverse, 5'-TCGTCTGAAGGCAGAGTCAGGA-3'; TGF- $\beta 1$ forward, 5'-TGACGTCACTGGAGTTGTACGG-3' and reverse, 5'-GGT TCATGTCATGGATGGTGC-3'; GAPDH forward, 5'-TGT GTCCGTCGTGGATCTGA-3' and reverse, 5'-CCTGCTTCA CCACCTTCTTGA-3'. The PCR program began with initial denaturation at $95^{\circ} \mathrm{C}$ for 10 min followed by 40 cycles of $95^{\circ} \mathrm{C}$ for $15 \mathrm{sec}$ and $58^{\circ} \mathrm{C}$ for $30 \mathrm{sec}$. The mRNA level was calculated using $2^{-\Delta \Delta \mathrm{Ct}}$ and normalized to GAPDH as described (16). Values are expressed as the fold change of the control.

Flow cytometry. To quantify the amount of Th17 and Treg cells, the mesenteric lymph nodes were cut into small pieces, incubated with $2.5 \mathrm{mM}$ EDTA at $37^{\circ} \mathrm{C}$ with agitation for $20 \mathrm{~min}$ to remove cells, minced and digested for $20 \mathrm{~min}$ at $37^{\circ} \mathrm{C}$ with $1 \mathrm{mg} / \mathrm{ml}$ collagenase type VIII (Sigma-Aldrich; Merck KGaA). The T cells were isolated using a Pan T-cell 
Isolation kit II (cat. no. 130-095-130; Miltenyi Biotec, Bergisch Gladbach, Germany). The isolated T cells were fixed and stained with anti-FoxP3 antibodies (cat. no. 130-098-119; 1:100; Miltenyi Biotec) or anti-IL-17A antibodies (cat. no. 130-103-007; 1:200; Miltenyi Biotec). Cell sorting analysis was performed on a FACSCalibur flow cytometer (BD Biosciences, Franklin Lakes, NJ, USA).

Western blot analysis. Total protein was extracted from colon tissue by using radioimmunoprecipitation assay lysis buffer $(150 \mathrm{mM} \mathrm{NaCl}, 1 \% \mathrm{NP}-40,0.1 \%$ SDS, $0.5 \%$ sodium deoxycholate, $50 \mathrm{mM}$ Tris- $\mathrm{HCl} \mathrm{pH} 7.4$ and $10 \%$ glycerol) supplemented with protease and phosphatase inhibitors (Roche Diagnostics, Basel, Switzerland). In total, $100 \mu \mathrm{g}$ protein per lane was subjected to 10 or $15 \%$ SDS-PAGE and then transferred to a nitrocellulose membrane (Thermo Fisher Scientific, Inc.). Membranes were blocked for $1 \mathrm{~h}$ in Tris-buffered saline containing 0.05\% Tween-20 (TTBS) and $5 \%$ bovine serum albumin (Sigma-Aldrich; Merck KGaA) or non-fat milk. Thereafter, membranes were incubated with the indicated primary antibodies (Santa Cruz Biotechnology, Inc., Dallas, TX, USA) at $4^{\circ} \mathrm{C}$ overnight, including mouse anti-TGF $\beta 1$ (cat. no. sc-130348; 1:600), mouse anti-caspase3 (cat. no. sc-136219; 1:1,000), mouse anti-cleaved caspase3 (cat. no. sc-271028; 1:500), rabbit anti-Bim (cat. no. sc-11425; 1:200), mouse anti-p38MAPK (cat. no. sc-7972; 1:1,000), rabbit anti-phospho-p38MAPK (cat. no. sc-17852-R; 1:1,000), mouse anti-JNK (cat. no. sc-7345; 1:500), anti-phospho-JNK (cat. no. sc-293136; 1:1,000), anti-c-Jun (cat. no. sc-166540; $1: 800)$ and mouse anti- $\beta$-actin (cat. no. sc-130300; 1:2,000). After 5 washes with TTBS, membranes were incubated with horseradish peroxidase-conjugated goat anti-mouse or rabbit immunoglobulin G (cat. no. sc-2005 and sc-2004, repectively; 1:5,000; Santa Cruz Biotechnology, Inc.) for $1 \mathrm{~h}$ at room temperature. Blots were developed with an enhanced chemiluminescence detection kit (cat. no. 32106; Pierce; Thermo Fisher Scientific, Inc.). The specific band was scanned and then quantified with ImageJ 1.49 software (National Institutes of Health, Bethesda, NJ, USA).

Statistical analysis. Values are expressed as the mean \pm standard deviation. Statistical evaluation was performed by using one-way analysis of variance (ANOVA) with Dunnett's multiple comparison post hoc tests for comparing multiple time-points in the same group or two-way ANOVA with Tukey's multiple comparison post-hoc tests for comparing multiple groups at multiple time-points with Prism 4.0 software (GraphPad Inc., La Jolla, CA, USA). P $\leq 0.05$ was considered to indicate a statistically significant difference.

\section{Results}

Effects of local TGF- $\beta 1$ levels on colon damage in TNBS-treated mice. In the present study, a mouse model of TNBS-induced colitis was used to investigate the effect of local TGF- $\beta 1$ levels on the severity of colon inflammation. As described previously (13), the TGF- $\beta 1$ levels in colon tissues were modulated by delivering different amounts of adenovirus expressing full-length mouse TGF- $\beta 1$. Colon TGF- $\beta 1$ levels were measured by using western blot and RT-qPCR. Compared with that in the control group, the protein abundance of TGF- $\beta 1$ in TNBS-treated mice was significantly higher at days 2, 5 and 7, and overexpression of TGF- $\beta 1$ was detected in TNBS-treated mice following adenoviral TGF- $\beta 1$ delivery (Fig. 1A). In addition, in comparison with those in the control group, the mRNA levels of TGF- $\beta 1$ in TNBS-treated mice were also significantly increased at days 2, 5 and 7. In TNBS-treated mice, adenoviral TGF- $\beta 1$ delivery led to a marked increase of TGF- $\beta 1 \mathrm{mRNA}$ in a dose-dependent manner (Fig. 1B). The levels of the active form of TGF- $\beta 1$ were also assessed using ELISA. Of note, the activated TGF- $\beta 1$ levels in TNBS-treated mice were not obviously changed over a time course of 14 days compared with those in the control group. However, delivery of adenoviral TGF- $\beta 1$ resulted in a dose-dependent increase of activated TGF- $\beta 1$ in TNBS-treated mice (Fig. 1C).

Colon damage was then evaluated by determining the macroscopic mucosal damage score (Table I). Compared with those in the control group, the colon damage score in TNBS-treated mice increased significantly over all time-points. In TNBS-treated mice, delivery of AdTGF-1 significantly decreased colon damage at days 2 and 5, and slightly decreased the score at days 7 and 14; however, there was no significant difference. By contrast, delivery of AdTGF-2 or AdTGF-3 significantly increased the colon damage score at days 2 and 14, and had no obvious effect on colon damage in TNBS-treated mice at days 5 and 7 (Table I).

The present study also assessed colon inflammation responses by determining the activities of MPO and ALP in colon tissue. MPO activity, directly associated with the neutrophil content, is commonly used for quantification of inflammation severity (17). Colonic inflammation is also characterized by an increase in AP activity, which has been mainly attributed to leucocyte activity (18). Compared with the control, a significant increase of MPO activity was detected in TNBS-treated mice at all time-points. Delivery of AdTGF-2 or AdTGF-3 further enhanced MPO activity in TNBS-treated mice, while delivery of AdTGF-1 markedly inhibited the TNBS-induced increase of MPO activation at days 2 and 5 (Table II). In comparison with the control, ALP activity also increased significantly at all time-points in TNBS-treated mice. Delivery of AdTGF-1 decreased TNBS-induced ALP activation at all time-points, and AdTGF-2 decreased TNBS-induced ALP activation at days 5, 7 and 14. However, ALP activity was not markedly affected in TNBS-treated mice following AdTGF-3 delivery (Table III). These results suggested that the colonic TGF $\beta-1$ levels may influence the severity of colon inflammation and damage in mice with TNBS-induced colitis.

Effects of colonic TGF- $\beta 1$ levels on dexamethasone efficacy in mice with TNBS-induced colon inflammation. Following adenoviral TGF- $\beta 1$ delivery, dexamethasone was administered to TNBS-treated mice once a day by orogastric gavage for 4 days. Compared with those in control mice, the colon damage score in the TNBS group were significantly increased. TNBS-induced colon damage was obviously alleviated by delivery of AdTGF-1 but was not influenced by AdTGF-2 and AdTGF-3. Of note, dexamethasone treatment significantly decreased the colon damage score in TNBS-treated mice receiving AdTGF-1 or AdTGF-2, while it had no effect in TNBS-induced mice receiving AdTGF-3 
A
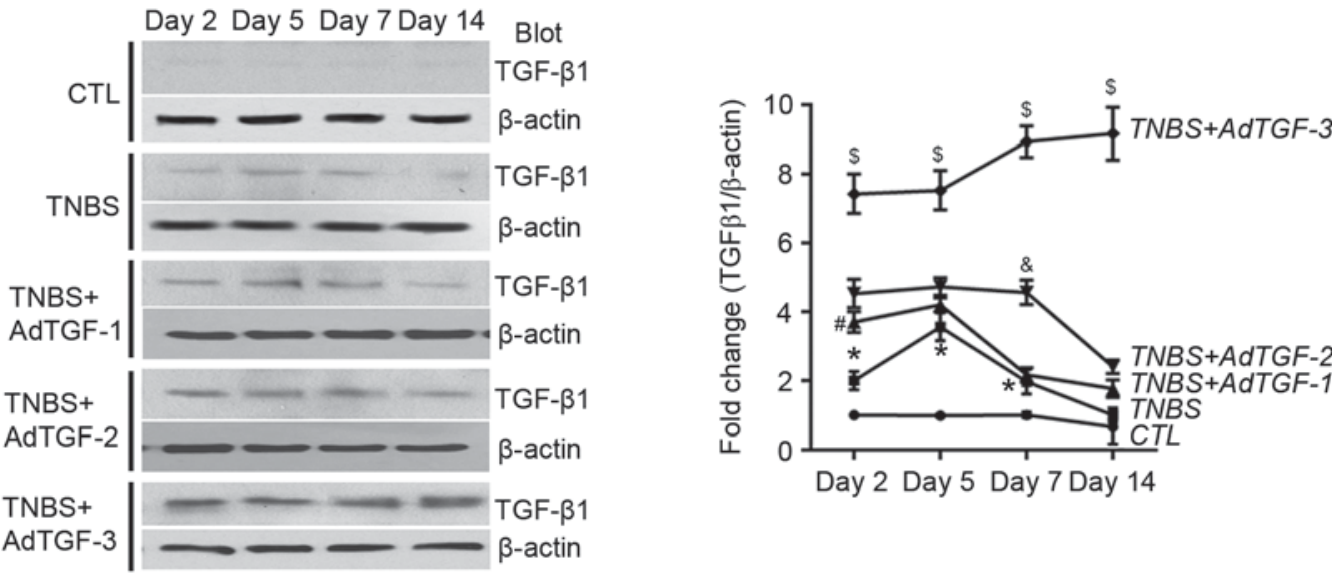

B

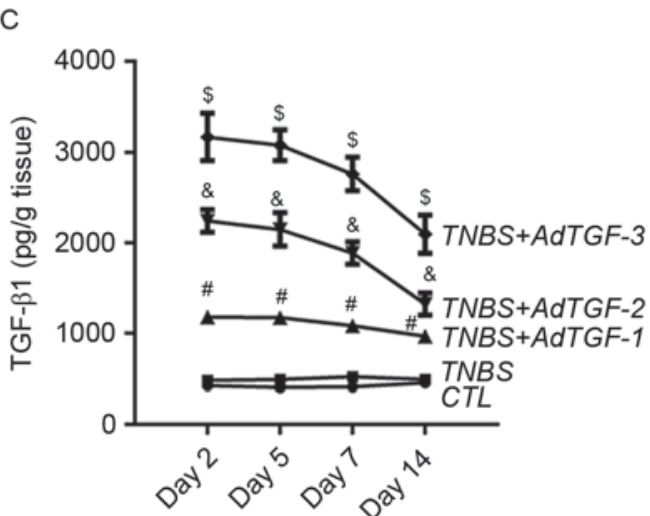

Figure 1. Evaluation of colon TGF- $\beta 1$ levels in TNBS mice receiving adTGF- $\beta 1$. Mice were challenged with TNBS by intrarectal administration. After $24 \mathrm{~h}$, a PBS enema containing adTGF- $\beta 1$ was given and allowed to express over a 14-day time-course. (A) Total protein was extracted from colon tissues and an immunoblot assay was performed for total TGF- $\beta 1$ protein level. (B) Total RNA was extracted from colon tissues and reversely transcribed to complementary DNA. The mRNA levels of TGF- $\beta 1$ was measured using quantitative polymerase chain reaction. (C) Homogenates of colon tissue were prepared and the active TGF- $\beta 1$ levels were assessed using ELISA. Doses: AdTGF-1, $1 \times 10^{7} \mathrm{pfu}$; AdTGF-2, $1 \times 10^{8} \mathrm{pfu}$; AdTGF-3, 1x10 pfu. Values are expressed as the mean \pm standard deviation ( $\mathrm{n}=4$ per group). ${ }^{\mathrm{P}} \mathrm{P}<0.05$ vs. CTL; ${ }^{\mathrm{P}} \mathrm{P}<0.05$ vs. TNBS; ${ }^{\circ} \mathrm{P}<0.05$ vs. TNBS + AdTGF-1; ${ }^{\mathrm{P}} \mathrm{P}<0.05$ vs. TNBS + AdTGF-2. CTL, control; TNBS, 2,4,6-trinitrobenzenesulfonic acid; AdTGF, adenovirus overexpressing transforming growth factor $\beta 1$.

(Fig. 2A). Compared with that in the control group, the ALP activity in TNBS-treated mice was significantly increased. Delivery of AdTGF-1 or AdTGF-2 significantly prevented TNBS-induced ALP activation, while AdTGF-3 had no effect on ALP activity in TNBS-treated mice. Dexamethasone treatment did not affect ALP activity in TNBS-induced mice receiving AdTGF-1 or AdTGF-2, while it markedly decreased the ALP activity in TNBS-induced mice receiving AdTGF-3 (Fig. 2B). In comparison with the control group, a significant increase of the MPO activity was detected in TNBS-treated mice, which was further increased by delivery of AdTGF-2 or AdTGF-3. Compared with that in the TNBS group, the activation level of MPO was decreased in TNBS-induced mice receiving AdTGF-1. Of note, in TNBS-treated mice receiving AdTGF-1 or AdTGF-2, the MPO activity was decreased by dexamethasone treatment in a significant manner. However, dexamethasone did not affect the MPO activity in TNBS mice receiving AdTGF-3 (Fig. 2C). Accordingly, the local TGF- $\beta 1$ levels not only affected colon damage but also influenced the efficacy of dexamethasone in mice with TNBS-induced colitis.

Effects of local TGF- $\beta 1$ levels and dexamethasone treatment on colonic cytokine secretion in TNBS-treated mice. The cytokine response is one of the major characteristics in
IBD (7). In the present study, the levels of the Th1-associated cytokine IFN- $\gamma$, the pro-inflammatory cytokines TNF- $\alpha$ and IL-6, the Th17-associated cytokines IL-23 and IL-17, and the Th2-associated cytokine IL-10 were assessed in the homogenates of colonic tissues (Fig. 3). Compared with those in the control group, the levels of IFN- $\gamma$, TNF- $\alpha$, IL-6, IL-17 and IL-23 increased significantly, while those of IL-10 decreased significantly in TNBS-treated mice. Of note, delivery of AdTGF-1 further increased, while that of AdTGF-3 further decreased the IL-10 levels in TNBS-treated mice. IL-10 levels were decreased in TNBS-treated mice following AdTGF-2 delivery. Dexamethasone treatment enhances the effect with AdTGF-1 on the IL-10 levels in TNBS-treated mice. Delivery of AdTGF-1 prevented TNBS-induced increases of IFN- $\gamma$, TNF- $\alpha$ and IL-23, but had no significant effect on the levels of IL-6 and IL-17. However, TNBS-induced increases of IFN- $\gamma$, IL-6 and IL-23 were enhanced by AdTGF-2 and AdTGF-3. The levels of TNF- $\alpha$ and IL-17 were further increased in TNBS-treated mice following AdTGF-3 delivery, while the effect of AdTGF-2 was not significant. Of note, dexamethasone treatment caused a downregulation of the levels of TNF- $\alpha$, IL- 6 , IL-17 and IL-23 in TNBS-induced mice receiving AdTGF-2, while it had no obvious effects in TNBS-treated mice receiving AdTGF-1 or AdTGF-3. However, dexamethasone treatment led 
Table I. Colonic damage score in mice with TNBS-induced intestinal inflammation following administration of AdTGF- $\beta 1$.

\begin{tabular}{lccccc}
\hline Time-point & CTL & TNBS & TNBS + AdTGF-1 & TNBS + AdTGF-2 & TNBS + AdTGF-3 \\
\hline Day 2 & $0.3 \pm 0.18$ & $5.6 \pm 0.23^{\mathrm{a}}$ & $4.2 \pm 0.12^{\mathrm{a}, \mathrm{b}}$ & $7.3 \pm 0.24^{\mathrm{a}, \mathrm{b}}$ & $8.3 \pm 0.14^{\mathrm{a}, \mathrm{b}}$ \\
Day 5 & $0.5 \pm 0.17$ & $8.6 \pm 0.23^{\mathrm{a}}$ & $6.1 \pm 0.19^{\mathrm{a}, \mathrm{b}}$ & $8.6 \pm 0.23^{\mathrm{a}}$ & $9.0 \pm 0.12^{\mathrm{a}}$ \\
Day 7 & $0.7 \pm 0.17$ & $7.3 \pm 0.18^{\mathrm{a}}$ & $6.5 \pm 0.24^{\mathrm{a}}$ & $7.8 \pm 0.12^{\mathrm{a}}$ & $8.2 \pm 0.11^{\mathrm{a}}$ \\
Day 14 & $0.6 \pm 0.12$ & $6.1 \pm 0.17^{\mathrm{a}}$ & $5.8 \pm 0.23^{\mathrm{a}}$ & $7.4 \pm 0.11^{\mathrm{a}, \mathrm{b}}$ & $7.7 \pm 0.18^{\mathrm{a}, \mathrm{b}}$ \\
\hline
\end{tabular}

Values are expressed as the mean \pm standard error of the mean $\left(\mathrm{n}=4\right.$ per group). ${ }^{\mathrm{a}} \mathrm{P}<0.05$ vs. control at the same time-point; ${ }^{\mathrm{b}} \mathrm{P}<0.05 \mathrm{vs}$. TNBS at the same time-point. CTL, control; TNBS, 2,4,6-trinitrobenzenesulfonic acid; AdTGF, adenovirus overexpressing transforming growth factor $\beta 1$.

Table II. Evaluation of myeloperoxidase activities (U/g colon tissue) in mice with TNBS-induced intestinal inflammation following administration of AdTGF- $\beta 1$.

\begin{tabular}{lcrrrr}
\hline Time-point & CTL & TNBS & TNBS + AdTGF-1 & TNBS + AdTGF-2 & TNBS + AdTGF-3 \\
\hline Day 2 & $6.63 \pm 0.83$ & $138.05 \pm 9.87^{\mathrm{a}}$ & $81.83 \pm 4.01^{\mathrm{a}, \mathrm{b}}$ & $175.43 \pm 6.54^{\mathrm{a}, \mathrm{b}}$ & $215.43 \pm 9.94^{\mathrm{a}, \mathrm{b}}$ \\
Day 5 & $6.07 \pm 0.76$ & $95.53 \pm 2.82^{\mathrm{a}}$ & $70.67 \pm 3.48^{\mathrm{a}, \mathrm{b}}$ & $156.00 \pm 7.58^{\mathrm{a}, \mathrm{b}}$ & $182.00 \pm 5.35^{\mathrm{a}, \mathrm{b}}$ \\
Day 7 & $6.87 \pm 0.64$ & $75.44 \pm 3.12^{\mathrm{a}}$ & $56.67 \pm 2.44^{\mathrm{a}}$ & $93.33 \pm 3.53^{\mathrm{a}}$ & $158.67 \pm 4.67^{\mathrm{a}, \mathrm{b}}$ \\
Day 14 & $6.67 \pm 0.67$ & $49.45 \pm 4.08^{\mathrm{a}}$ & $34.07 \pm 4.19^{\mathrm{a}}$ & $80.40 \pm 2.69^{\mathrm{a}, \mathrm{b}}$ & $110.77 \pm 5.82^{\mathrm{a}, \mathrm{b}}$ \\
\hline
\end{tabular}

Values are expressed as the mean \pm standard error of the mean ( $\mathrm{n}=4$ per group). ${ }^{\mathrm{a}} \mathrm{P}<0.05$ vs. control at the same time-point; ${ }^{\mathrm{b}} \mathrm{P}<0.05 \mathrm{vs}$. TNBS at the same time-point. CTL, control; TNBS, 2,4,6-trinitrobenzenesulfonic acid; AdTGF, adenovirus overexpressing transforming growth factor $\beta 1$.

Table III. Evaluation of ALP (U/mg protein of colon tissue) activities in mice with TNBS-induced intestinal inflammation following administration of AdTGF- $\beta 1$.

\begin{tabular}{lccccc}
\hline Time-point & CTL & TNBS & TNBS + AdTGF-1 & TNBS + AdTGF-2 & TNBS + AdTGF-3 \\
\hline Day 2 & $0.507 \pm 0.052$ & $1.150 \pm 0.065^{\mathrm{a}}$ & $0.660 \pm 0.057^{\mathrm{b}}$ & $1.000 \pm 0.058^{\mathrm{a}}$ & $1.212 \pm 0.043^{\mathrm{a}}$ \\
Day 5 & $0.510 \pm 0.085$ & $1.775 \pm 0.085^{\mathrm{a}}$ & $0.700 \pm 0.029^{\mathrm{b}}$ & $0.816 \pm 0.044^{\mathrm{a}, \mathrm{b}}$ & $1.935 \pm 0.062^{\mathrm{a}}$ \\
Day 7 & $0.527 \pm 0.037$ & $1.583 \pm 0.044^{\mathrm{a}}$ & $0.722 \pm 0.032^{\mathrm{b}}$ & $0.800 \pm 0.058^{\mathrm{a}, \mathrm{b}}$ & $1.462 \pm 0.055^{\mathrm{a}}$ \\
Day 14 & $0.537 \pm 0.052$ & $1.496 \pm 0.055^{\mathrm{a}}$ & $0.830 \pm 0.047^{\mathrm{a}, \mathrm{b}}$ & $0.700 \pm 0.058^{\mathrm{a}, \mathrm{b}}$ & $1.332 \pm 0.064^{\mathrm{a}}$
\end{tabular}

Values are expressed as the mean \pm standard error of the mean ( $\mathrm{n}=4$ per group). ${ }^{\mathrm{a}} \mathrm{P}<0.05$ vs. control at the same time-point; ${ }^{\mathrm{b}} \mathrm{P}<0.05 \mathrm{vs}$. TNBS at the same time-point. CTL, control; TNBS, 2,4,6-trinitrobenzenesulfonic acid; AdTGF, adenovirus overexpressing transforming growth factor $\beta 1$.

to a downregulation of the levels of IFN- $\gamma$ in TNBS-induced mice receiving AdTGF-1 and AdTGF-2, and had no effects on IFN- $\gamma$ levels in TNBS mice receiving AdTGF-3. Therefore, the results of the present study suggested that the local TGF- $\beta 1$ levels may determine the efficacy of dexamethasone in regulating the balance of cytokines in mice with TNBS-induced colitis.

Effects of local TGF- $\beta 1$ levels and dexamethasone treatment on regulating the balance of Th17 and Treg cells in mesenteric lymph nodes of TNBS-treated mice. To investigate the role of Treg and Th17 cells in mice with TNBS-induced colitis, the fraction of Treg and Th17 cells in mesenteric lymph nodes was assessed. Furthermore, the levels of transcription factors Foxp3 for Treg cells and ROR $\gamma$ t for Th17 cells were analyzed using
RT-qPCR (Fig. 4A). Compared with those in the control, the mRNA levels of ROR $\gamma$ t increased significantly in TNBS-treated mice, which was further increased by the delivery of AdTGF-3, but not by AdTGF-1 or AdTGF-2. Dexamethasone treatment had no effect on the ROR $\gamma \mathrm{t}$ mRNA levels in TNBS-induced mice receiving adenoviral TGF- $\beta 1$. As compared with the control, TNBS enema led to a significant decrease of Foxp3 mRNA, which was inhibited by AdTGF-1. However, AdTGF-3 further decreased Foxp3 mRNA levels in TNBS-treated mice. Of note, dexamethasone treatment prevented the reduction of Foxp3 mRNA in TNBS-treated mice receiving AdTGF-2, and had an enhancing effect on upregulating the Foxp3 mRNA levels with AdTGF-1 in TNBS-treated mice (Fig. 4A).

To understand the role of TGF- $\beta 1$ levels and dexamethasone treatment in regulating the balance of Treg and Th17 cells 
A

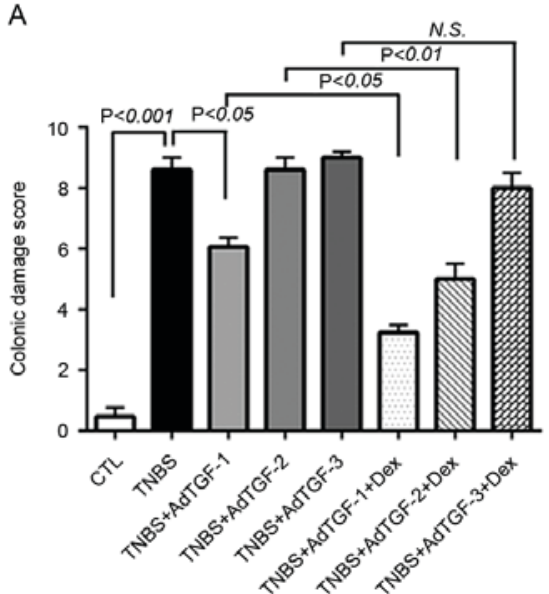

B

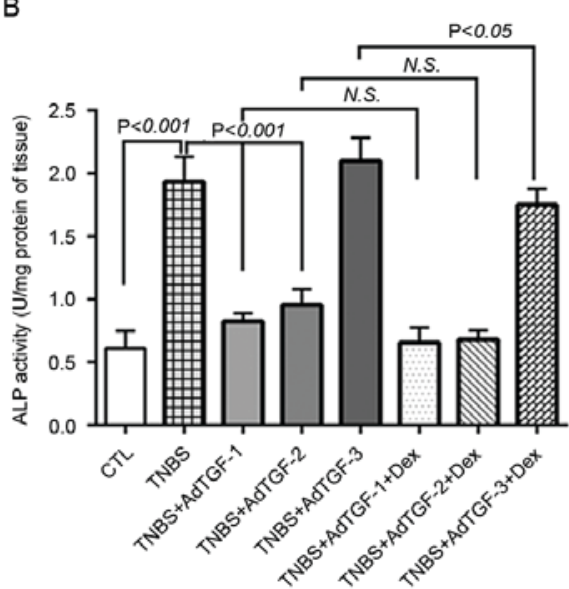

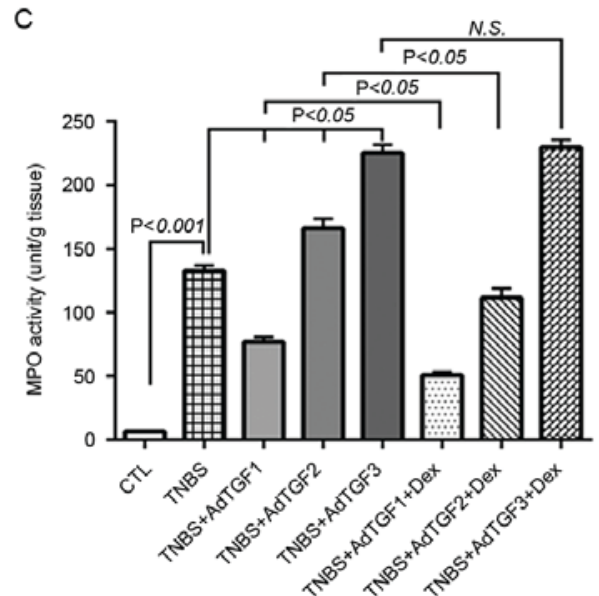

Figure 2. Effects of local TGF- $\beta 1$ levels on dexamethasone efficacy in mice with TNBS-induced colitis. AdTGF- $\beta 1$ was delivered to the colons of TNBS mice and dexamethasone $(5 \mathrm{mg} / \mathrm{kg}$ body weight) was given once a day by orogastric gavage for 4 days. (A) The colonic damage score was determined to evaluate macroscopic mucosal damage. (B) Colon tissue protein was extracted with a lysis buffer composed of $20 \mathrm{mM}$ Tris- $\mathrm{HCl}$ (pH 7.5 ), $150 \mathrm{mM} \mathrm{NaCl}$ and $1 \%$ Triton X-100, and ALP activity was determined. (C) Homogenates of colon tissues were prepared and evaluated for MPO enzymatic activity. Doses: AdTGF-1, $1 \times 10^{7}$ pfu; AdTGF-2, $1 \times 10^{8}$ pfu; AdTGF-3, $1 \times 10^{9}$ pfu. Values are expressed as the mean \pm standard deviation (n=4 per group). N.S., no significance; MPO, myeloperoxidase; ALP, alkaline phosphatase; CTL, control; TNBS, 2,4,6-trinitrobenzenesulfonic acid; AdTGF, adenovirus overexpressing transforming growth factor $\beta 1$; Dex, dexamethasone.
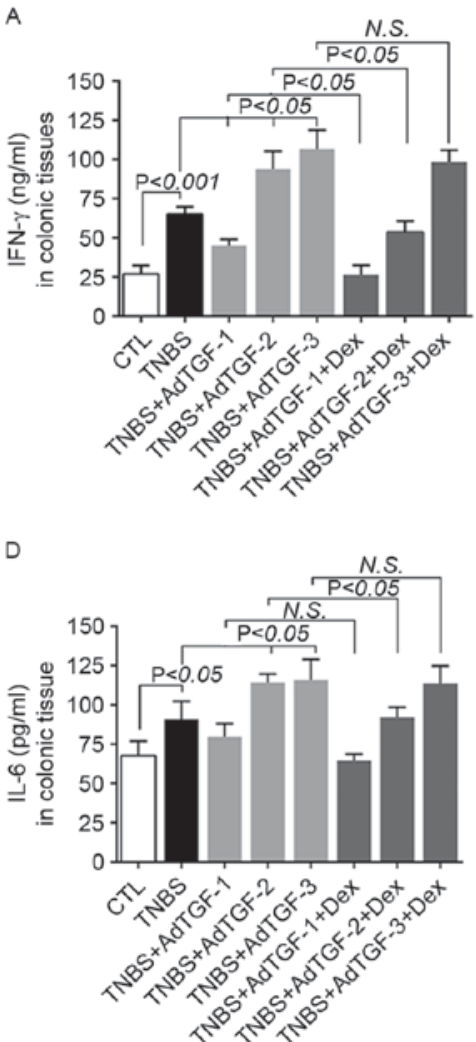
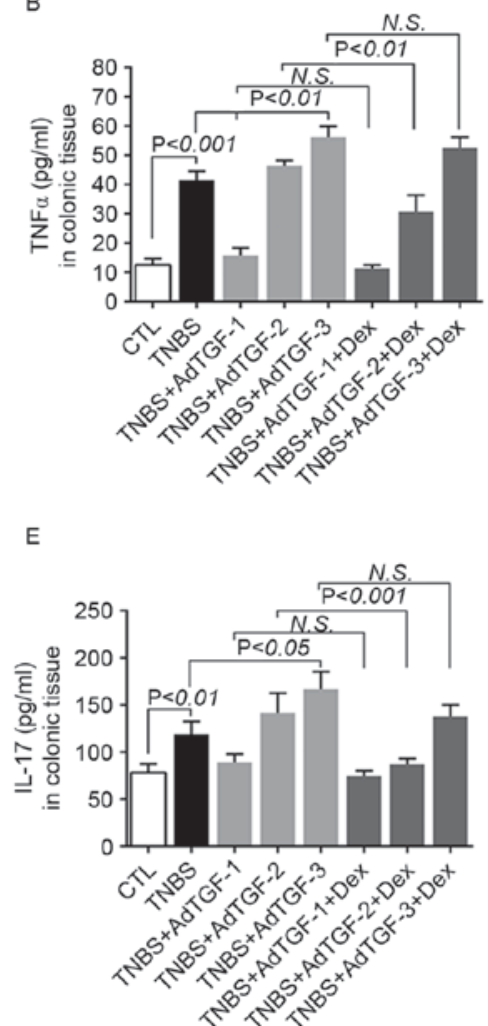
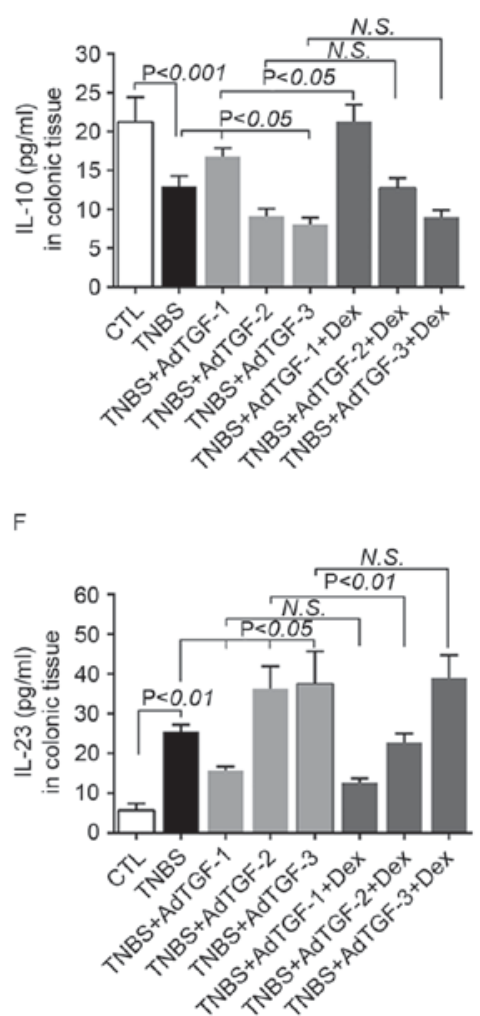

Figure 3. Effects of local TGF- $\beta 1$ levels and dexamethasone treatment on colon cytokine secretion in TNBS-treated mice. AdTGF- $\beta 1$ was delivered to the colons of TNBS mice and dexamethasone $(5 \mathrm{mg} / \mathrm{kg}$ body weight) was given once a day by orogastric gavage for 4 days. Homogenates of colonic tissues were used to measure the levels of (A) IFN- $\gamma$, (B) TNF- $\alpha$, (C) IL-10, (D) IL-6, (E) IL-17 and (F) IL-23. Doses: AdTGF-1, 1x10 pfu; AdTGF-2, 1x10 pfu; AdTGF-3, $1 \times 10^{9} \mathrm{pfu}$. Values are expressed as the mean \pm standard deviation ( $\mathrm{n}=4$ per group). N.S., no significance; IFN, interferon; IL, interleukin; TNF, tumor necrosis factor; CTL, control; TNBS, 2,4,6-trinitrobenzenesulfonic acid; AdTGF, adenovirus overexpressing transforming growth factor $\beta 1$; Dex, dexamethasone.

in TNBS-treated mice, the present study analyzed the fraction of Treg and Th17 cells in mesenteric lymph nodes using flow cytometry (Fig. 4B). Compared with the control, the percentage of Th17 cells increased significantly in TNBS-treated mice, which was further increased following AdTGF-3 delivery.
Dexamethasone had no effects on the percentage of Th17 cells in TNBS mice receiving adenoviral TGF- $\beta 1$. In addition, the reduction of Treg cells in TNBS-treated mice was prevented by AdTGF-1 delivery. However, delivery of AdTGF-2 and AdTGF-3 further and significantly decreased the Treg cell 
A
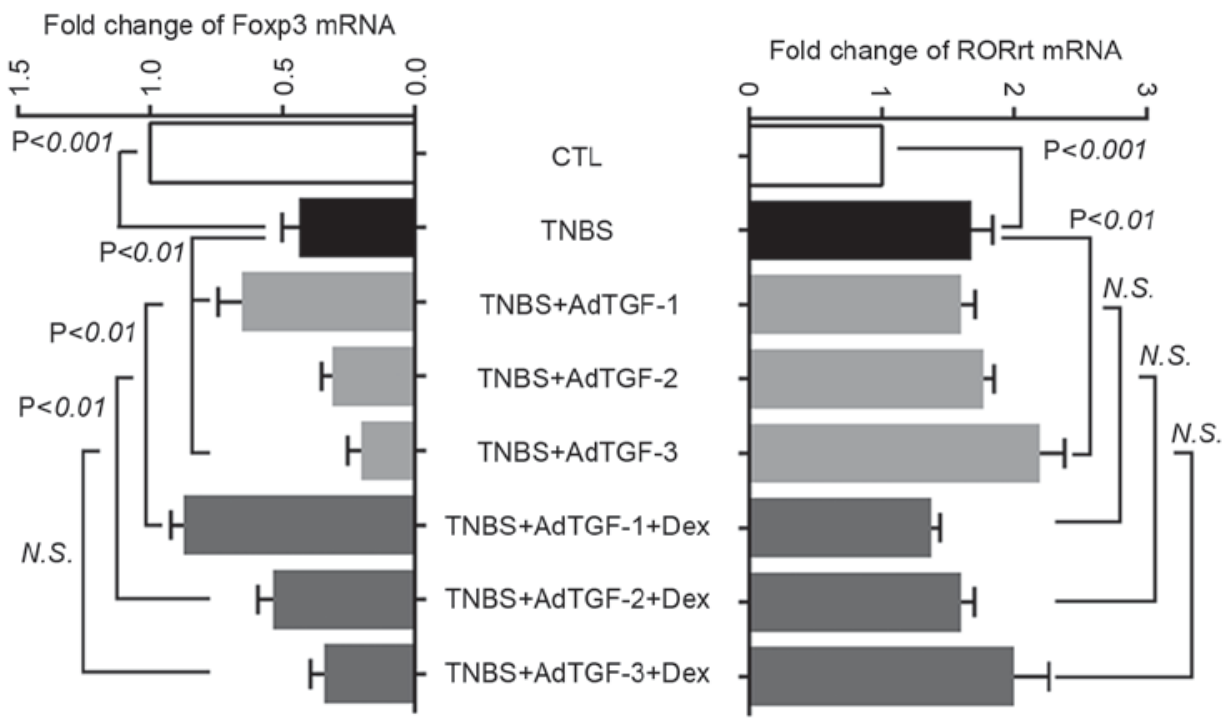

B $\%$ of Treg cells in MLN
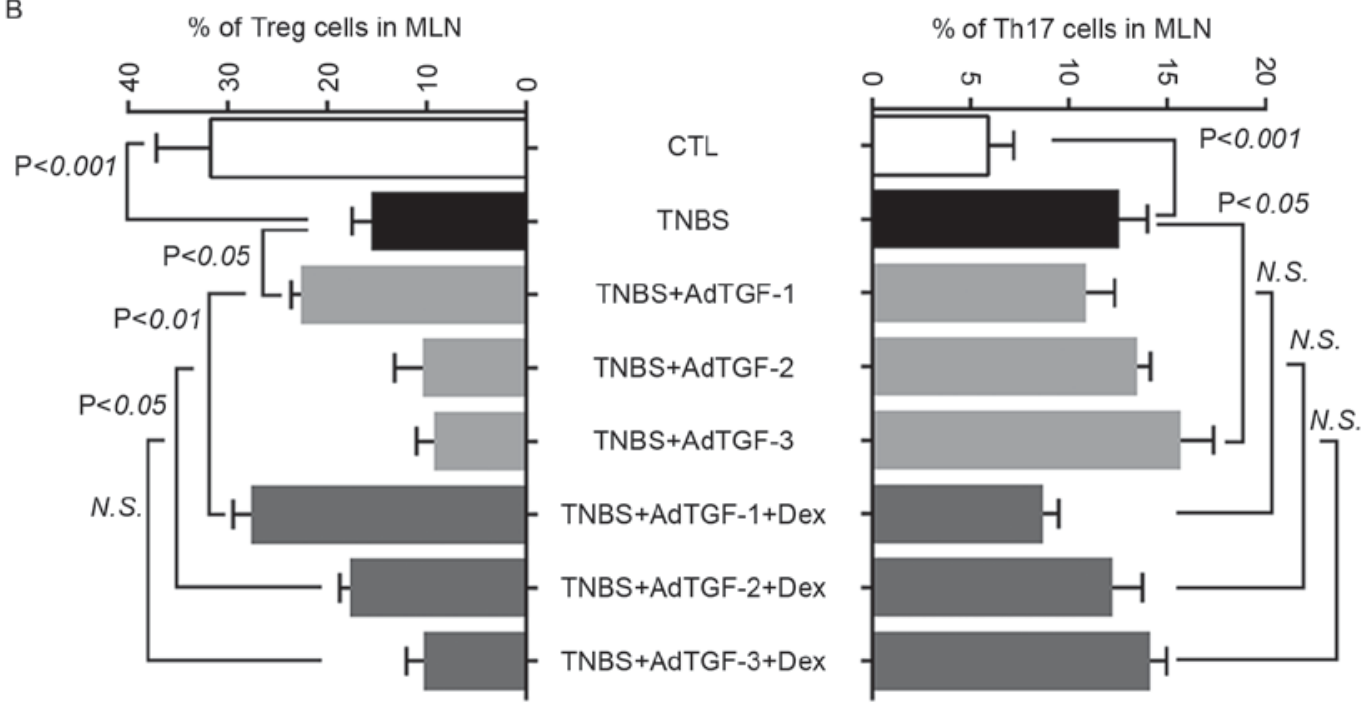

Figure 4. Effects of local TGF- $\beta 1$ levels and dexamethasone treatment on regulating the balance of Th17 cells and Tregs in mesenteric lymph nodes of TNBS-treated mice. AdTGF- $\beta 1$ was delivered to the colons of TNBS mice and dexamethasone $(5 \mathrm{mg} / \mathrm{kg}$ body weight) was given once a day by orogastric gavage for 4 days. (A) Total RNA was extracted from mesenteric lymph nodes and reversely transcribed to complementary DNA. Real time polymerase chain reaction analysis was performed to evaluate the levels of transcription factors Foxp3 and ROR $\gamma \mathrm{t}$. (B) The fraction of Treg and Th17 cells in mesenteric lymph

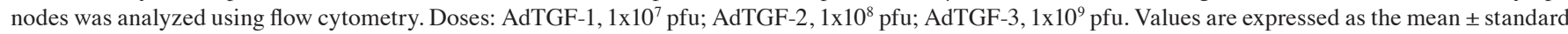
deviation ( $\mathrm{n}=4$ per group). N.S., no significance; MLN, mesenteric lymph nodes; CTL, control; TNBS, 2,4,6-trinitrobenzenesulfonic acid; AdTGF, adenovirus overexpressing transforming growth factor $\beta 1$; Dex, dexamethasone; Foxp3, forkhead box p3; ROR, RAR-related orphan receptor; Treg, T-regulatory cell; Th17 cell, type 17 T-helper cell.

population in TNBS mice. Dexamethasone prevented the reduction of Treg cells in TNBS-treated mice receiving AdTGF-2 and had an enhancing effect on upregulating the percentage of Treg cells with AdTGF-1 (Fig. 4B). However, dexamethasone treatment did not change the number of Treg cells in TNBS mice receiving AdTGF-3. These results suggested that local TGF- $\beta 1$ levels may affect the balance of Treg and Th17 cells in TNBS-induced mice colitis, and demonstrated that the efficacy of dexamethasone may be influenced by the local TGF- $\beta 1$ levels. In addition, dexamethasone alleviated TNBS-induced colon damage predominantly by upregulating Treg cells.

Effects of local TGF- $\beta 1$ levels and dexamethasone treatment on cytokines in mesenteric lymph nodes of TNBS-treated mice.
Homogenates were prepared from mesenteric lymph nodes and the levels of cytokines IL-10 and IL-23 were determined using ELISA (Fig. 5). Compared with those in the control group, the levels of IL-23 increased significantly in TNBS-treated mice and were further increased by delivery of AdTGF-3, but not AdTGF-1 and AdTGF-2. Dexamethasone treatment had no effects on the IL-23 levels in TNBS mice receiving adenoviral TGF- $\beta 1$. In comparison with the control, TNBS enema led to a marked reduction of IL-10, which was prevented by AdTGF-1, but not AdTGF-2 or AdTGF-3. Dexamethasone enhanced the effect of AdTGF-1 delivery on increasing the IL-10 levels in TNBS-treated mice. In TNBS mice receiving AdTGF-2 and AdTGF-3, the levels of IL-10 were not altered following dexamethasone treatment. These results indicated that the TGF- $\beta 1$ levels determined the secretion of IL-10 and IL-23, and that 
A

IL-10 (pg/ml) in MLN

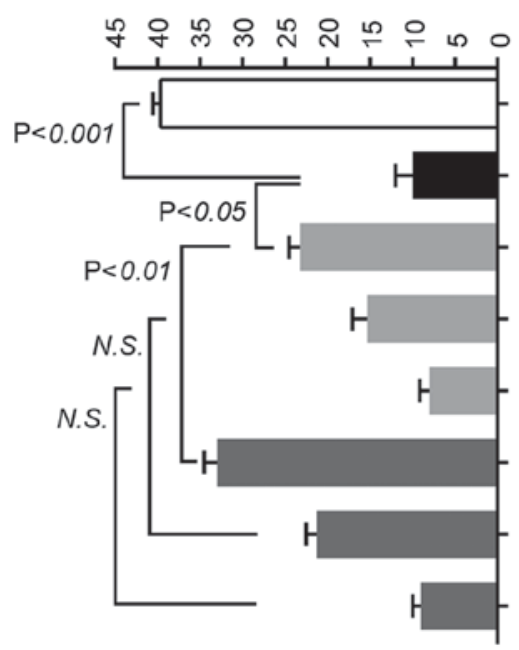

B

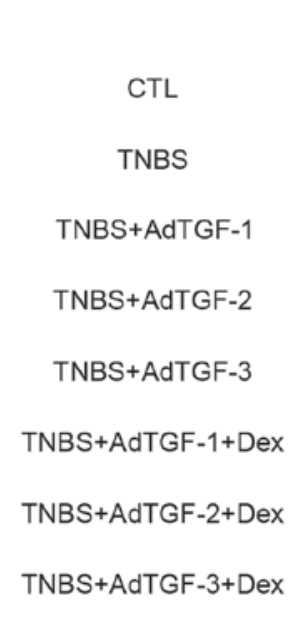

IL-23 (pg/ml) in MLN

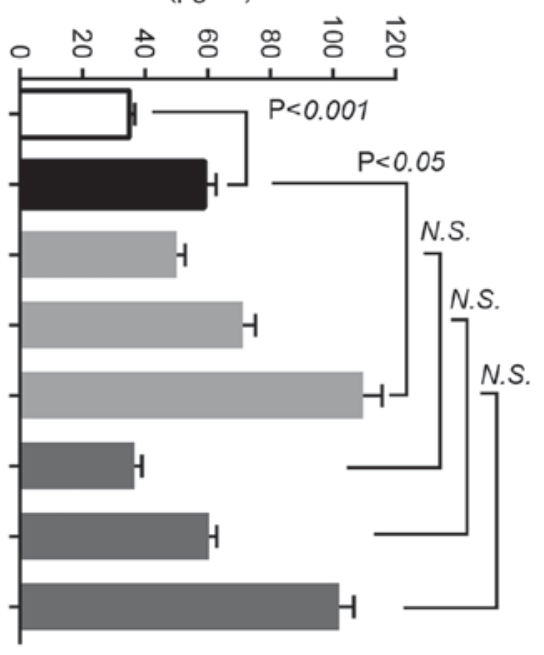

Figure 5. Effects of local TGF- $\beta 1$ levels and dexamethasone treatment on the cytokine concentration in mesenteric lymph nodes of TNBS-treated mice. AdTGF- $\beta 1$ was delivered to the colons of TNBS mice and dexamethasone $(5 \mathrm{mg} / \mathrm{kg}$ body weight) was given once a day by orogastric gavage for 4 days. Homogenates of mesenteric lymph nodes were prepared and the levels of cytokines (A) IL-10 and (B) IL-23 were determined using ELISA. Doses: AdTGF-1, $1 \times 10^{7}$ pfu; AdTGF-2, $1 \times 10^{8}$ pfu; AdTGF-3, $1 \times 10^{9}$ pfu. Values are expressed as the mean \pm standard deviation (n=4 per group). N.S., no significance; MLN, mesenteric lymph nodes; CTL, control; TNBS, 2,4,6-trinitrobenzenesulfonic acid; AdTGF, adenovirus overexpressing transforming growth factor $\beta 1$; Dex, dexamethasone; IL, interleukin.

dexamethasone predominantly upregulated IL-10 levels, which was associated with the levels of TGF- $\beta 1$.

Effects of local TGF- $\beta 1$ levels and dexamethasone treatment on apoptosis of colon tissues in TNBS-treated mice. The expression of the apoptotic proteins caspase 3 and Bim was evaluated using western blot analysis (Fig. 6A). As compared with the control, the levels of active caspase 3 and Bim increased significantly in TNBS-treated mice. TNBS-induced upregulation of activated caspase 3 was significantly prevented by delivery of AdTGF. Of note, dexamethasone treatment decreased the active caspase 3 levels in TNBS mice receiving adTGF1. In TNBS-treated mice, increases in Bim were significantly inhibited by delivery of AdTGF-1 and AdTGF-2, but not AdTGF-3. However, dexamethasone treatment had no effect on the Bim levels in TNBS-induced mice receiving adenoviral TGF- $\beta 1$. The present study also evaluated the activity of the p38MAPK/JNK/c-Jun signaling pathway (Fig. 6B). Compared with the control, the TNBS-induced activation of p38MAPK, JNK and c-Jun was significantly prevented by adenoviral TGF- $\beta 1$ delivery, particularly by AdTGF-1 and AdTGF-2. Of note, dexamethasone treatment had an enhancing effect on AdTGF-1 and AdTGF-2 by downregulating phospho-p38MAPK, phospho-JNK and c-Jun in TNBS-treated mice. These results indicated that dexamethasone may prevent colon tissue apoptosis by inhibiting activation of the $\mathrm{p} 38 \mathrm{MAPK} / \mathrm{JNK} / \mathrm{c}$-Jun pathway, wherein the local TGF- $\beta 1$ levels have an important role.

\section{Discussion}

Dexamethasone, a synthetic glucocorticoid with enhanced potency, has been widely used as an anti-inflammatory immunosuppressive agent in the treatment of $\operatorname{IBD}(19,20)$. In experimental IBD models, it was demonstrated that dexamethasone and prednisone suppressed the inflammatory response through a variety of mechanisms, including decreasing the activity of nuclear factor- $\kappa \mathrm{B}$ and reducing heparanase and heat shock protein 70 expression $(21,22)$. The present study investigated the effects of local TGF- $\beta 1$ levels on the anti-inflammatory role of dexamethasone by focusing on the differentiation of Treg and Th17 cells in an experimental TNBS-induced IBD model. It was revealed that the abundance of TGF- $\beta 1$ in the colon increased significantly in TNBS-treated mice compared with those in the control group, whereas its activated level exhibited no difference between TNBS and control mice over a 14-day period. Vallance et al (13) reported that delivering adenoviral vectors encoding spontaneously active TGF- $\beta 1$ into the colons of normal mice led to a severe and prolonged inflammatory response as well as localized collagen deposition, leading to progressive fibrosis. Actually, various amounts of TGF- $\beta 1$ were reported to be present in the colons of patients with IBD $(10,12,23)$, which may influence the efficacy of anti-inflammatory agents, since TGF- $\beta 1$ has disparate roles in the pathogenesis of IBD by either stimulating or suppressing the immune system (24). To mimic the variability of TGF- $\beta 1$ levels in human IBD patients, the present study delivered three different doses of adenoviral vector encoding full-length murine TGF- $\beta 1$, not its active form, into the colons of TNBS mice. Overproduced TGF- $\beta 1$ and the increased active form were obtained in a dose-dependent manner in TNBS mice following adenoviral TGF- $\beta 1$ delivery. The present study then evaluated colonic damage as well as MPO and ALP activity in TNBS mice receiving adenoviral TGF- $\beta 1$ and dexamethasone. MPO and ALP enzymatic activity has been considered a sensitive biochemical marker of colonic inflammation, and their inhibition may be interpreted as a result of an anti-inflammatory effect $(17,18)$. The present results indicated that local TGF- $\beta 1$ levels modulate TNBS-induced colon damage as well as MPO and ALP activation, and that the efficacy of dexamethasone 
A
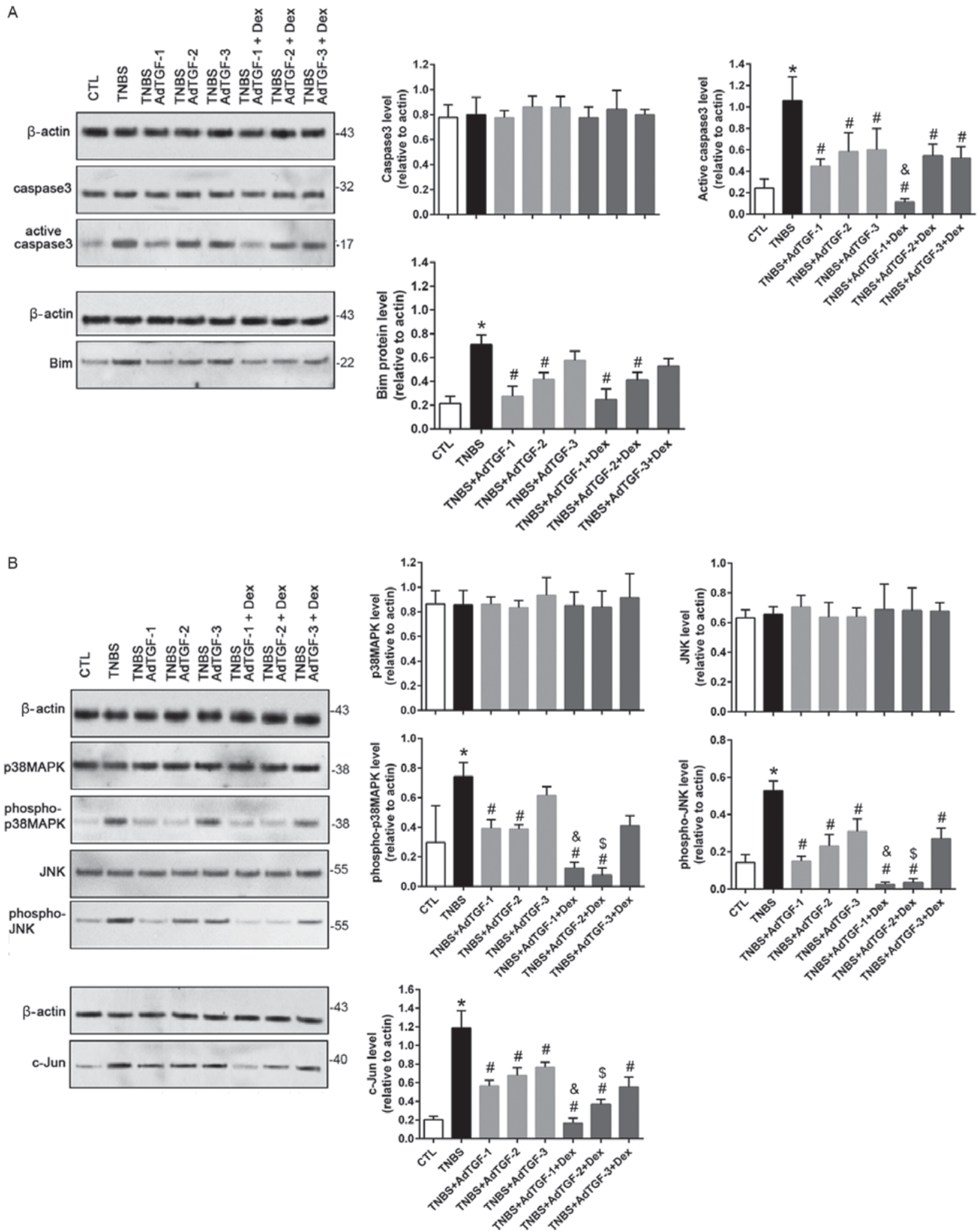

Figure 6. Effects of local TGF- $\beta 1$ levels and dexamethasone treatment on colon tissue apoptosis in TNBS-treated mice. AdTGF- $\beta 1$ was delivered to the colons of TNBS mice and dexamethasone $(5 \mathrm{mg} / \mathrm{kg}$ body weight) was given once a day by orogastric gavage for 4 days. Total protein was extracted from colonic tissues using radioimmunoprecipitation assay lysis buffer. Expression of (A) the apoptotic proteins caspase3 and Bim as well as (B) p38MAPK/JNK/c-Jun

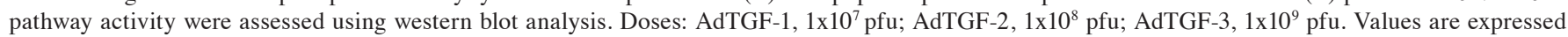
as the mean \pm standard deviation ( $\mathrm{n}=4$ per group). ${ }^{\mathrm{P}}<0.05$ vs. $\mathrm{CTL} ;{ }^{*} \mathrm{P}<0.05$ vs. TNBS; ${ }^{\circledR} \mathrm{P}<0.05$ vs. TNBS + AdTGF-1; ${ }^{\mathrm{P}}<0.05$ vs. TNBS + AdTGF-2 CTL, control; TNBS, 2,4,6-trinitrobenzenesulfonic acid; AdTGF, adenovirus overexpressing transforming growth factor $\beta 1$; Dex, dexamethasone; MAPK, mitogen-activated protein kinase; JNK, c-Jun N-terminal kinase; SD, standard deviation.

depends on the abundance of local TGF- $\beta 1$ in TNBS-induced mouse colitis. In a previous study, TNBS-induced rat colitis was also ameliorated by intraperitoneal gene therapy with plasmid DNA encoding native TGF- $\beta$ (25). 
In inflammation, TGF- $\beta 1$ has a key regulatory role and is required for the induction of the differentiation and maturation of Treg cells that control the immune response (6). Alternatively, in the presence of IL-6, TGF- $\beta 1$ may initiate the production of Th17 cells that have a crucial role in promoting and/or maintaining chronic inflammatory diseases (26). Accordingly, the cytokine profile of colonic tissues was assessed in the present study. In TNBS mice, a significant elevation in pro-inflammatory cytokines was detected, including TNF- $\alpha$, IFN- $\gamma$, IL-6, IL-17 and IL-23, while the anti-inflammatory cytokine IL-10 was significantly reduced. The profile of cytokines in TNBS-treated mice was significantly altered following delivery of adenoviral TGF- $\beta 1$. The low amount, AdTGF-1, significantly decreased the production of pro-inflammatory cytokines, particularly IFN- $\gamma$, TNF- $\alpha$ and IL-23, while it significantly increased the levels of IL-10. By contrast, the high amount, AdTGF-3, exerted a reverse role in the regulation of cytokine production. The present study also identified that dexamethasone treatment had an enhancing effect with AdTGF-1 on reducing cytokine production particularly on IFN- $\gamma$ and IL-10. In TNBS mice receiving AdTGF-2, the increases of IFN- $\gamma$, TNF, IL-6, IL-17 and IL-23 were significantly prevented by dexamethasone application. However, dexamethasone had no effects on the levels of cytokines in TNBS mice receiving a high amount of AdTGF-3. The present study suggested that the local TGF- $\beta 1$ levels may affect the severity of colon inflammation and determined their effect on the efficacy of dexamethasone in the treatment of IBD. A study on TNBS-induced rat colitis reported that prednisolone treatment prevented the production of IL-6, IL-1, TNF- $\alpha$ and IFN- $\gamma$ (22). Furthermore, dexmedetomidine, a selective $\alpha 2$-adrenergic receptor agonist, led to amelioration of TNBS-induced colitis in mice, likely by increasing IL-4 and IL-10 levels as well as reducing IL-23 levels (27). The cytokines that induce Th17 cell lineage development likely include IL-6, IL-21, IL-1 $\beta$ and IL-23, with a synergistic role for TGF- $\beta 1$ (28). Th17 cells are thought to predominantly produce IL-17, particularly IL-17A and IL-17F, as well as IL-23 (28). IL-10 is the major cytokine produced by Treg cells (6). Based on the alteration of the cytokine profile, the present results suggested that Treg and Th17 cells may be involved in TNBS-induced colitis. Of note, decreased IL-23 levels may facilitate the marked increase of IL-10 in TNBS-induced mice treated with a low amount of TGF- $\beta 1$. Although IL-23 promotes the secretion of IL-17 from Th17 cells by binding to its receptor on Th17 cells, Th17 cells deficient in IL-23 may secret the anti-inflammatory cytokine IL-10 (29).

To analyze the alteration of the fraction of Treg and Th17 cells, the present study assessed the mRNA levels of their specific transcription factors Foxp3 and ROR $\gamma \mathrm{t}$, and their percentage in mesenteric lymph nodes. The mesenteric lymph nodes lie between the layers of the mesentery, are hundreds in number and help the body to fight disease. IBDs such as Crohn's disease or ulcerative colitis are common inflammatory conditions linked to mesenteric lymphadenitis (30). Compared with the control, the present study identified increased Th17 and decreased Treg cells in TNBS-treated mice. Furthermore, adenoviral TGF- $\beta 1$ delivery and dexamethasone treatment had no effect on Th17 cells in TNBS-treated mice. However, delivery of a low amount of AdTGF- $\beta 1$ prevented the TNBS-induced reduction of Treg cells, with a potential enhancing role for dexamethasone treatment. Results consistent with this were obtained from the analysis of the cytokines IL-10 and IL-23. The present study indicated that in TNBS-treated mice, the balance of Th17 and Treg cells was disrupted and the cytokine profile was therefore altered, and that dexamethasone treatment mainly promoted the production of Treg cells under low levels of TGF- $\beta 1$.

The present study further evaluated the expression levels of apoptotic proteins and the activation levels of the p38MAPK/JNK/c-Jun signaling pathway in colon tissues. Immunoblot analysis demonstrated that TNBS-induced upregulation of activated caspase 3 and Bim was inhibited by AdTGF- $\beta 1$ delivery mainly at the low concentration. Dexamethasone treatment further decreased the levels of activated caspase 3 in TNBS mice receiving adenoviral TGF- $\beta 1$, particularly at the low concentration, while it had no obvious effect on Bim. Furthermore, activation of the p38MAPK/JNK/c-Jun pathway was detected in TNBS-treated mice, which was inhibited predominantly by AdTGF-1 and AdTGF-2. Dexamethasone treatment further decreased the levels of phospo-p38MAPK, phospho-JNK and c-Jun in TNBS mice receiving AdTGF-1 and AdTGF-2. Accordingly, the present results suggested that the p38MAPK/JNK/c-Jun pathway may be involved in the inhibitory function of lows amounts of TGF- $\beta 1$ delivered to the colons of mice with TNBS-induced colon damage. In addition, dexamethasone may protect the colon against damage through inhibition of the p38MAPK/JNK/c-Jun pathway depending on the local levels of TGF- $\beta 1$. Similarly, a previous study detected elevated levels of active caspase 3 and phosphorylated p38MAPK in mice with TNBS-induced colitis (31). In an in vitro TNF- $\alpha$-induced HT29 intestinal epithelial cell apoptosis model, p38MAPK phosphorylation was increased (31). It was also reported that the JNK inhibitor XG-102 protects against TNBS-induced mouse colitis, where the production of TNF- $\alpha$, expression of Bim, B-cell lymphoma 2-associated X protein and p53 as well as activation of caspase 3 and JNK substrate c-Jun were significantly reduced (32).

Taken together, the results of the present study demonstrated that low amounts of TGF- $\beta 1$ delivered to the colon alleviate the inflammatory response and damage of colon tissue, mainly by restoring the levels of Treg cells in TNBS-treated mice. The present study also provided evidence that the therapeutic effect of dexamethasone may depend on the local levels of TGF- $\beta 1$ in TNBS-induced colitis at least partially through promoting the differentiation of Treg cells and thus altering the balance of the pro- and anti-inflammatory cytokines. In addition, dexamethasone may protect the colon against damage through inhibition of the $\mathrm{p} 38 \mathrm{MAPK} / \mathrm{JNK} / \mathrm{c}-\mathrm{Jun}$ pathway in the presence of low levels of TGF- $\beta 1$.

\section{Acknowledgements}

Not applicable.

\section{Funding}

This study was supported by the National Natural Science Foundation of China (grant no. 81170357 to P.Y.). 


\section{Availability of data and materials}

Not applicable.

\section{Authors' contributions}

PY and YL designed the project and planned the experiments. $\mathrm{PY}, \mathrm{NC}$ and LS performed the experiments and analyzed the data. TP and GC contributed to the animal sample preparation and the interpretation of the results. PY wrote the manuscript with support from NC and LS. All authors discussed the results and contributed to the final manuscript.

\section{Ethics approval and consent to participate}

All of the animal protocols were approved by the Experimental Animal Ethics Committee of Peking University People's Hospital (Beijing, China).

\section{Consent for publication}

Not applicable.

\section{Competing interests}

The authors declare that they have no competing interests.

\section{References}

1. Molodecky NA, Soon IS, Rabi DM, Ghali WA, Ferris M Chernoff G, Benchimol EI, Panaccione R, Ghosh S, Barkema HW and Kaplan GG: Increasing incidence and prevalence of the inflammatory bowel diseases with time, based on systematic review. Gastroenterology 142: 46-54.e42, 2012.

2. de Lange KM and Barrett JC: Understanding inflammatory bowel disease via immunogenetics. J Autoimmun 64: 91-100, 2015.

3. Kaistha A and Levine J: Inflammatory bowel disease: The classic gastrointestinal autoimmune disease. Curr Probl Pediatr Adolesc Health Care 44: 328-334, 2014

4. Lee YK and Mazmanian SK: Has the microbiota played a critical role in the evolution of the adaptive immune system? Science 330: 1768-1773, 2010.

5. Powrie F, Leach MW, Mauze S, Caddle LB and Coffman RL: Phenotypically distinct subsets of $\mathrm{CD} 4^{+} \mathrm{T}$ cells induce or protect from chronic intestinal inflammation in C. B-17 scid mice. Int Immunol 5: 461-471, 1993.

6. Himmel ME, Yao Y, Orban PC, Steiner TS and Levings MK: Regulatory T-cell therapy for inflammatory bowel disease: More questions than answers. Immunology 136: 115-122, 2012.

7. Neurath MF: Cytokines in inflammatory bowel disease. Nat Rev Immunol 14: 329-342, 2014.

8. Goettel JA, Scott Algood HM, Olivares-Villagómez D Washington MK, Chaturvedi R, Wilson KT, Van Kaer L and Polk DB: KSR1 protects from interleukin-10 deficiency-induced colitis in mice by suppressing T-lymphocyte interferon- $\gamma$ production. Gastroenterology 140: 265-274, 2011.

9. Strober W and Fuss IJ: Proinflammatory cytokines in the pathogenesis of inflammatory bowel diseases. Gastroenterology 140 1756-1767, 2011.

10. Feagins LA: Role of transforming growth factor- $\beta$ in inflammatory bowel disease and colitis-associated colon cancer. Inflamm Bowel Dis 16: 1963-1968, 2010.

11. Kajdaniuk D, Marek B, Borgiel-Marek H and Kos-Kudła B Transforming growth factor $\beta 1$ (TGF $\beta 1$ ) in physiology and pathology. Endokrynol Pol 64: 384-396, 2013.

12. Marafini I, Zorzi F, Codazza S, Pallone F and Monteleone G: TGF-Beta signaling manipulation as potential therapy for IBD. Curr Drug Targets 14: 1400-1404, 2013.
13. Vallance BA, Gunawan MI, Hewlett B, Bercik P, Van Kampen C, Galeazzi F, Sime PJ, Gauldie J and Collins SM: TGF-betal gene transfer to the mouse colon leads to intestinal fibrosis. Am J Physiol Gastrointest Liver Physio 289: G116-G128, 2005.

14. Kitani A, Fuss IJ, Nakamura K, Schwartz OM, Usui T and Strober W: Treatment of experimental (Trinitrobenzene sulfonic acid) colitis by intranasal administration of transforming growth factor (TGF)-betal plasmid: TGF-betal-mediated suppression of $\mathrm{T}$ helper cell type 1 response occurs by interleukin (IL)-10 induction and IL-12 receptor beta2 chain downregulation. J Exp Med 192: 41-52, 2000.

15. Wallace JL and Keenan CM: An orally active inhibitor of leukotriene synthesis accelerates healing in a rat model of colitis. Am J Physiol 258: G527-G534, 1990.

16. Livak KJ and Schmittgen TD: Analysis of relative gene expression data using real-time quantitative PCR and the 2(-Delta Delta C(T)) method. Methods 25: 402-408, 2001.

17. Zheng L, Gao ZQ and Wang SX: A chronic ulcerative colitis model in rats. World J Gastroenterol 6: 150-152, 2000.

18. Sánchez de Medina F, Martinez-Augustin O, González R, Ballester I, Nieto A, Gálvez J and Zarzuelo A: Induction of alkaline phosphatase in the inflamed intestine: A novel pharmacological target for inflammatory bowel disease. Biochem Pharmacol 68: 2317-2326, 2004.

19. Friend DR: Review article: Issues in oral administration of locally acting glucocorticosteroids for treatment of inflammatory bowel disease. Aliment Pharmacol Ther 12: 591-603, 1998.

20. de Mattos BR, Garcia MP, Nogueira JB, Paiatto LN, Albuquerque CG, Souza CL, Fernandes LG, Tamashiro WM and Simioni PU: Inflammatory bowel disease: An overview of immune mechanisms and biological treatments. Mediators Inflamm 2015: 493012, 2015.

21. Scheinman RI, Gualberto A, Jewell CM, Cidlowski JA and Baldwin AS Jr: Characterization of mechanisms involved in transrepression of NF-kappa B by activated glucocorticoid receptors. Mol Cell Biol 15: 943-953, 1995.

22. Quaglio AE, Castilho AC and Di Stasi LC: Experimental evidence of heparanase, Hsp70 and $\mathrm{NF}-\kappa \mathrm{B}$ gene expression on the response of anti-inflammatory drugs in TNBS-induced colonic inflammation. Life Sci 141: 179-187, 2015.

23. Del Zotto B, Mumolo G, Pronio AM, Montesani C, Tersigni R and Boirivant M: TGF-betal production in inflammatory bowel disease: Differing production patterns in Crohn's disease and ulcerative colitis. Clin Exp Immunol 134: 120-126, 2003.

24. Monteleone G, Boirivant M, Pallone F and MacDonald TT: TGF-beta1 and Smad7 in the regulation of IBD. Mucosal Immunology 1 (Suppl 1): S50-S53, 2008.

25. Giladi E, Raz E, Karmeli F, Okon E and Rachmilewitz D. Transforming growth factor-beta gene therapy ameliorates experimental colitis in rats. Eur J Gastroenterol Hepatol 7: 341-347, 1995.

26. Schmitt N and Ueno H: Regulation of human helper T cell subset differentiation by cytokines. Curr Opin Immunol 34: 130-136, 2015.

27. Erdogan Kayhan G, Gul M, Kayhan B, Gedik E, Ozgul U, Kurtoglu EL, Durmus M and Ersoy MÖ: Dexmedetomidine ameliorates TNBS-induced colitis by inducing immunomodulator effect. J Surg Res 183: 733-741, 2013.

28. Marwaha AK, Leung NJ, McMurchy AN and Levings MK: TH17 cells in autoimmunity and immunodeficiency: Protective or pathogenic? Front Immunol 3: 129, 2012.

29. McGeachey MJ, Bak-Jensen KS, Chen Y, Tato CM, Blumenschein W, McClanahan T and Cua DJ: TGF-beta and IL-6 drive the production of IL-17 and IL-10 by T cells and restrain $\mathrm{T}(\mathrm{H})-17$ cell-mediated pathology. Nat Immunol 8: 1390-1397, 2007.

30. Hartog A, Belle FN, Bastiaans J, de Graaff P, Garssen J, Harthoorn LF and Vos AP: A potential role for regulatory T-cells in the amelioration of DSS induced colitis by dietary non-digestible polysaccharides. J Nutr Biochem 26: 227-233, 2015.

31. Zhang D, Wang L, Yan L, Miao X, Gong C, Xiao M, Ni R and Tang Q: Vacuolar protein sorting 4B regulates apoptosis of intestinal epithelial cells via p38 MAPK in Crohn's disease. Exp Mol Pathol 98: 55-64, 2015.

32. Reinecke K, Eminel S, Dierck F, Roessner W, Kersting S, Chromik AM, Gavrilova O, Laukevicience A, Leuschner I, Waetzig V, et al: The JNK inhibitor XG-102 protects against TNBS-induced colitis. PLoS One 7: e30985, 2012. 